\title{
Antimicrobial and Thermal Properties of Coating Systems Modified with ZnO Nanoparticle and its Hybrid Forms: (A Review)
}

\author{
TOLUTOPE O. SIYANBOLA ${ }^{1 *}$, ABIODUN F. AKINSOLA ${ }^{2}$, JOSEPH A. ADEKOYA ${ }^{1}$, \\ OLAYINKA O. AJANI' ${ }^{1}$, CYRIL O. EHI-EROMOSELE ${ }^{1}$, GRACE I. OLASEHINDE ${ }^{3}$ and \\ ADESOLA A. AJAYI ${ }^{3}$
}

'Department of Chemistry, Covenant University, P.M.B. 1023, Ota, Ogun State, Nigeria.

${ }^{2}$ Department of Chemistry, Ekiti State University, P.M.B. 5363, Ado-Ekiti, Nigeria.

${ }^{3}$ Department of Biological Sciences, Covenant University, P.M.B. 1023, Ota, Ogun State, Nigeria.

${ }^{*}$ Corresponding Author E-mail: tolu.siyanbola@ covenantuniversity.edu.ng

http://dx.doi.org/10.13005/ojc/330102

(Received: December 04, 2016; Accepted: February 08, 2017)

\begin{abstract}
This review examines the unparalleled chemical and physical properties of $\mathrm{ZnO}$ nanoparticles and its hybrid forms. The influence of these multifunctional materials within the polymeric matrix of organic coatings was discussed. The scanning electron microscope is seen to provide relevant information about the dispersion of the hybrid and composite coating systems. This review provides concise information about the antimicrobial and thermal stability of composites.
\end{abstract}

Keywords: Nanoparticles, hybrid, coatings, antimicrobial, thermal stability.

\section{INTRODUCTION}

The concerns over the increase in worldwide epidemic and infectious diseases have accentuated the need to design antibiotics and promoting sanitary practices. World smallest life (microbes) are establised to be the most virulent since the stone age. Diseases like malaria caused by protozoa (Plasmodium spp), pneumonia caused by bacterial, fungus and virus, White pox caused by Serratia marcescens, whooping cough (Bordetella pertussis) and tuberculosis (Mycobacterium tuberculosis) top the list of world infectious diseases ${ }^{1}$. Microbes such as Escherichia, Streptococci and Staphylococci are responsible for most hospital (nosocomial) infections. The United States of American alone have a statistical record of two (2) million cases of hospital acquired infections and about 90,000 deaths per year ${ }^{2}$. The development of drugs such as antibiotics have helped to reduce the deadliness of the infections. Years after there applications (i.e. antibiotics), scientists have noticed the resistant strains of bacteria to designed antibiotics. The misuse, protracted use and bacterial 
evolution was observed to have caused the resistant strain. The campaign against microbes have geared manufacturals towards formulating products like mouthwash, room spray, kitchen soaps, glass cleaner, shampoo, surface cleaners and perfume with antifungi and antibacterial chemicals ${ }^{3}$. The instinctual ability of bacteria to attach itself to surfaces and form thin colonies layers, which (for example) is capable of covering medical device surfaces and thereby creating medium of infection could be tackled by developing coating formulations able to inhibit its growth. Devices like catheters, mechanical heart valves, contact lenses, intrauterine devices, surgical consumables and orthopedic implants can become mediums for infection if not rightly protected ${ }^{4}$. There are various types of protection that could inhibit the growth of these microbes. This review primarily emphasis the formulation of eco-friendly coating systems modified with $\mathrm{ZnO}$ nanoparticles and its hybrid forms derived from seed oils. Coating systems are formulations uniquely designed for surface covering of substrates. They provides functional, decorative, and in some cases both on its applied substrate $^{5}$. Plant seed oils based coating systems has recently been studied by researchers in a bid to substitute those derived from conventional petrochemicals base coating systems. Unlike petrochemical feed stocks that create environmental concerns ranging from air to water pollutions and global warming disaster; plant seed oils are renewable biodegradable resource materials that can be formulated into effective coating systems ${ }^{6-8}$. However, the nature of most plant seed oils (i.e. the composition of their fatty acid profiles) deters them from been used directly in coating formulations hence, the need to modify the seed oils in other to create reactive functional sites. Modified polyols systems prepared through aminolysis, transestrification, hydroformylation, epoxidation, partial glyceride (PG) formation, blown oil are pathways towards creating functional sites for coating systems ${ }^{8-11}$. Coating systems such as polyesteramides, polyetheramides, polyesteramide-urethanes are synthesized from plant base polyol platforms as exemplified in Scheme $1^{8,10}$. The synthesized pristine organic coating products however shows limited thermal, corrosion, antimicrobial, rigidity, and chemical characteristic properties required in structural applications ${ }^{12}$ ${ }^{14}$. It is in the light of this, that researchers are incorporating designed nanoparticles within the polymeric matrix of pristine coatings in order to reinforce the characteristic properties of the polymer composite thereby, creating innovative solutions in the area of optics, electronics, biomedical and material science. Quite a number of nanoparticles have been used in composite coating formulation processes. Commonly used based nanoparticles in this regard are $\mathrm{TiO}_{2}, \mathrm{Al}_{2} \mathrm{O}_{3}, \mathrm{SiO}_{2}, \mathrm{CaCO}_{3}, \mathrm{ZnO}$, etc. The later (i.e. $\mathrm{ZnO}$ nanoparticle) possesses unique characteristics such as improved chemical, biological, semi-conductor properties and drug delivery. Nano-sized $\mathrm{ZnO}$ particles have also been found to be inert, non-toxic in nature and possess a blanket for UV radiation (due to its wide band gap of $3.37 \mathrm{eV}$, large bond strength and its heavy $60 \mathrm{meV}$ excitation binding energy at room temperature) ${ }^{15-18}$. The inorganic amphoteric oxide (i.e. $\mathrm{ZnO}$ ) is nearly insoluble in water and reacts slowly with fatty acids of triglycerides hence, the need to modify the periphery hydroxyls functional groups of the $\mathrm{ZnO}$ with organic compounds ${ }^{19-20}$. This will provide the required ambience for reaction between the triglyceride polyols, polyesters, polyethers and urethanes with the modified hybrid $\mathrm{ZnO}$ nanoparticles. This paper aims to review synthesis routes of preparing organic coating composites via the introduction of hybrid $\mathrm{ZnO}$ nanoparticles (ZnO-APTMS or ZnO-APTES) within the pristine polymer matrix and discussed thermal and corrosion stabilities, chemical resistance and antimicrobial sensitivity of seed oil based coating composites. Section 2 present basic discussions on $\mathrm{ZnO}$ nanoparticle and synthesis routes for preparation of hybrid- $\mathrm{ZnO}$ nanoparticles and its composites. In section 3, property evaluations (such as thermal stability, corrosion studies, chemical resistance and antimicrobial sensitivity) of coating composites were reviewed. The concluding remarks are presented in section 4 .

\section{ZnO nanoparticles}

Over the years, $\mathrm{ZnO}$ nanoparticles have received extensive attention owing to its versatile industrial applications. The symmetric center deficiency in its wurtzite structure model (Figure 1) compounded with wide electromechanical coupling ensues in strong pyroelectric and piezoelectric properties. These effects results in the use of $\mathrm{ZnO}$ material in mechanical actuators and piezoelectric sensors ${ }^{21}$. This inorganic metal oxide $(\mathrm{ZnO})$ with high thermal and mechanical stability at room 
temperature belongs to group II-IV semiconductor and has its covalence between ionic and covalent semiconductors limits $22-23$.

The conductometric method of analysis shows that the antibacterial activity of $\mathrm{CaO}, \mathrm{MgO}$ and $\mathrm{ZnO}$ can be ascribed to the reactive surface oxygen species on these oxides ${ }^{24}$. These inorganic oxides contain requisite mineral elements in human systems, which when administered in small amounts present antimicrobial agent tendencies. This tendency is reported to be dependent on the particulate size of these oxides ${ }^{25}$. This multifunctional material $(\mathrm{ZnO})$ creates new chemistries for organic base coatings. However, ZnO nanoparticles have significant tendency to agglomerate in coating systems. Hence, the need to modify the hydroxyl functional peripheral groups of $\mathrm{ZnO}$ nanoparticles especially via solgel method of creating hybrid materials (Scheme 2) for various industrial applications, such as the

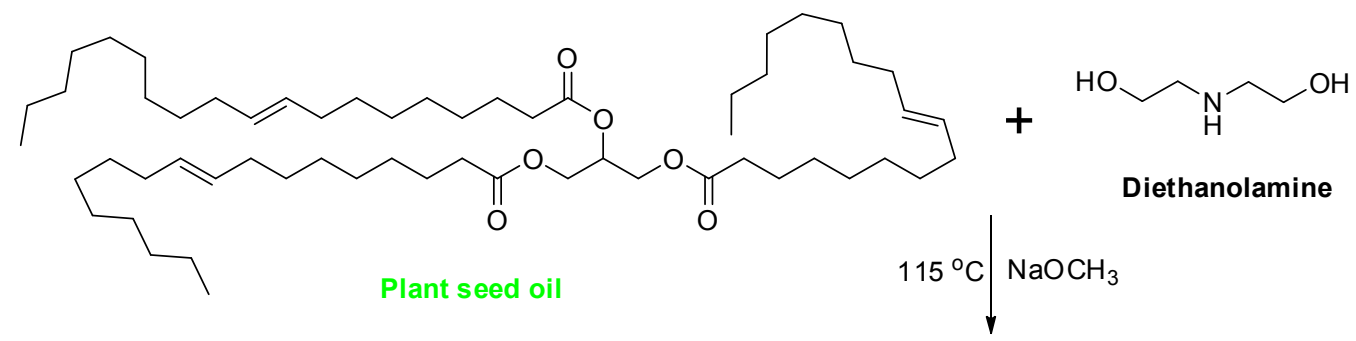

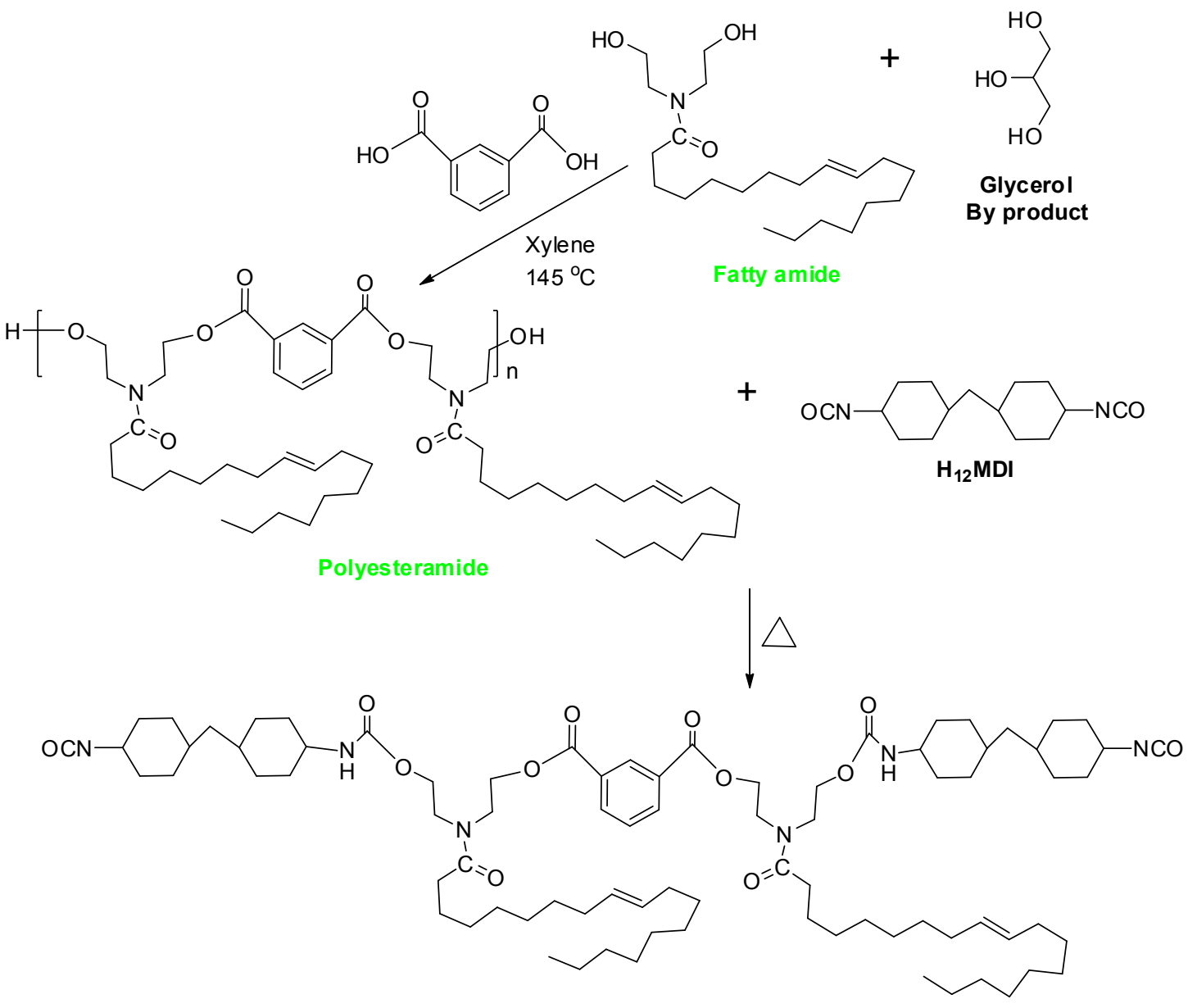

Polyes teramide-urethane

Scheme 1: Synthesis of polyesteramide-urethane 
preparation of adhesives and coatings ${ }^{26}$. This method is simple, reliable, low cost, and repeatable synthetic route that provides for it surface modifications ${ }^{27}$.

Synthesis of hybrid-ZnO (ZnO-APTMS or ZnOAPTES) nanoparticles and its seed oil based composites

Recently, researchers have designed several methods of modifying the surface of $\mathrm{ZnO}$ material in a bid to reducing the effect of agglomeration and intercalation (when combined with other materials such as montmorillonite) without impairing the physicochemical properties of the compound $^{28}$. The following sections present scientific contributions towards modifying $\mathrm{ZnO}$ hybrid systems and composites formulations for coating purposes.

Dhoke et $a^{29}$ reported an attempt to synthesize a nano-composite by incorporating nano$\mathrm{ZnO}$ within a developed alkyd-based waterborne coating at different loading percentages. The composite were synthesized by combining alkydbased waterborne coating with hexamethylolmelamine as cross-linker in the mixing ratio of 70:30. This base matrix coating was treated with $0.01,0.02$, and 0.03 wt.\% nano-ZnO. Dispersion was carried out using mechanical stirrer initially then culminating with ultrasonication. The application of the coating was

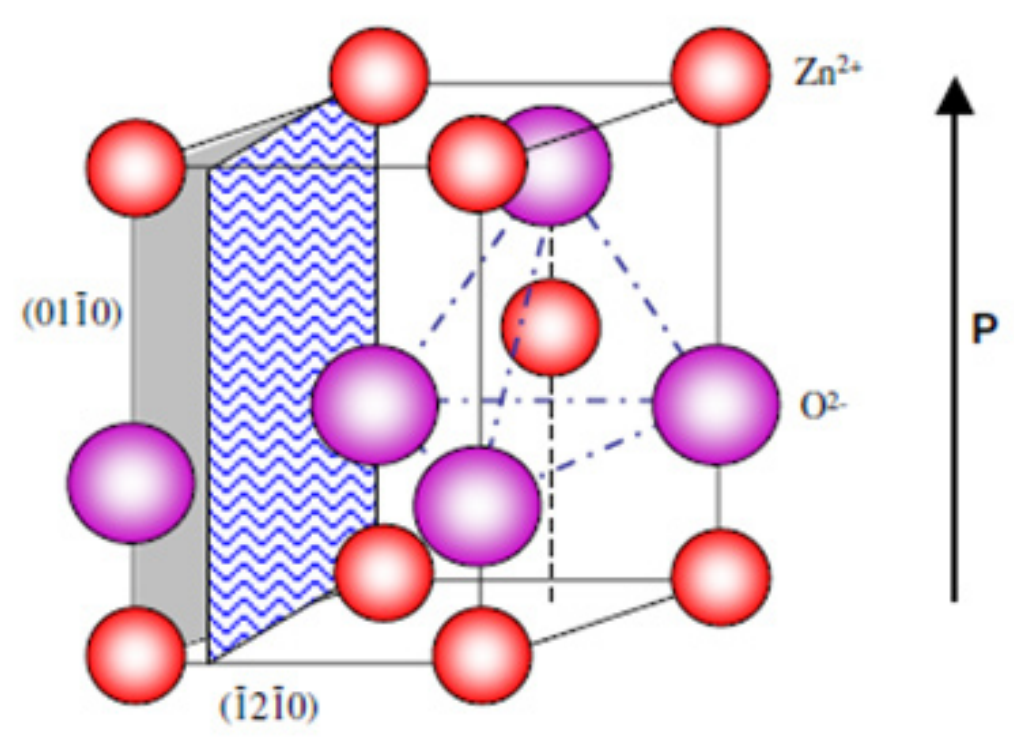

Fig. 1: Wurtzite structure model of $\mathrm{ZnO}^{17}$<smiles>CO[Si](CCCN)(OC)OC</smiles>

Scheme 2: Surface modification of $\mathrm{ZnO}$ nanoparticles 
done via dipping of pretreated mild steel panels in the coating (nanocomposite). Curing was at $130 \stackrel{\circ}{\mathrm{C}}$ for 15 minutes. Similar procedure was reported by Dhoke et $\mathrm{al}^{30}$ were mechanical and heat-resistance properties of waterborne silicone-modified alkydbased coatings were investigated alongside effect of nano-ZnO addition. Li et $\mathrm{al}^{31}$ prepared reinforced polyurethane coatings by mixing hydroxyl-acrylic resin (HAR) with an average molecular weight of 15,600 and hexamethylene-1,6-diisocyanate (HDI trimer). Planetary ball milling instrument was used in mixing along with percentages of $\mathrm{ZnO}$ nanoparticles. $30 \mathrm{~g}$ of thinner was mixed with some $\mathrm{ZnO}$ nanoparticles for 1.5 hour at $40 \mathrm{rpm}$. Subsequently, the suspension obtained was agitated with $40 \mathrm{~g} \mathrm{HAR}$ and $10 \mathrm{~g}$ of HDI trimer. The mixture was later ball-milled for 1 hour at 40 rpm. Reinforced polyurethane composite coatings were later prepared. Jena et a ${ }^{32}$ modified the peripheral of $\mathrm{ZnO}$ with 3-aminopropyl-triethoxysilane and afterwards incorporate the 3-aminopropyl- triethoxysilane$\mathrm{ZnO}$ (APTES-ZnO) within the polymeric matrix of hyperbranched polyurethane-urea. This was achieved by adding $10 \mathrm{~g}$ of $\mathrm{ZnO}$ into a $50 \mathrm{~g}$ toluene in a round bottomed flask. The content was stirred with a magnetic stirrer for 5 minutes. Ultrasonic bath was used to improve the solubility of $\mathrm{ZnO}$ in toluene. $1 \mathrm{~g}$ of APTES coupling agent was added to the suspension and stirred at room temperature. After the appearance of a yellow-transparent dispersion the mixture was refluxed for 24 hours. Rotatory evaporator was used to dry the modified material. Unreacted APTES molecules were removed by washing with ethanol (3 times). The resultant power

Table 1: Antimicrobial activity of pure polymer and PGU-APTMS-ZnO hybrid coatings ${ }^{33}$

\begin{tabular}{|c|c|c|c|c|c|}
\hline Sample & $\begin{array}{l}\text { Bacillus } \\
\text { subtilis }\end{array}$ & $\begin{array}{c}\text { Staphylococcus } \\
\text { aureus }\end{array}$ & E. coli & $\begin{array}{c}\text { Klebsiella } \\
\text { pneumonia }\end{array}$ & $\begin{array}{c}\text { Aspergillus } \\
\text { niger }\end{array}$ \\
\hline PGU & - & - & + & - & - \\
\hline PGU-1\% APTMS-ZnO & - & + & + & ++ & N.D \\
\hline PGU-1.5\% APTMS-ZnO & - & ++ & ++ & + & N.D \\
\hline PGU-2\% APTMS-ZnO & - & +++ & +++ & ++ & +++ \\
\hline
\end{tabular}

"+" indicates the sample showed antibacterial activity, "-"implies no antibacterial activity

N.D indicates not determined

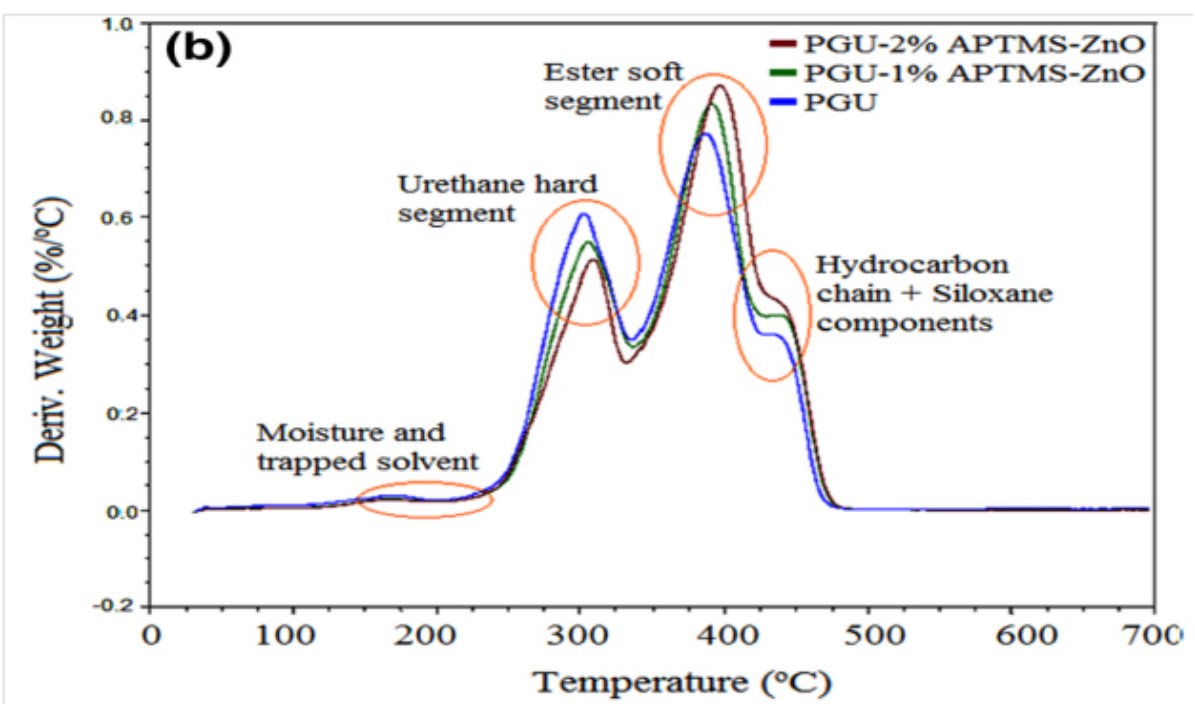

Fig. 2: Differential thermogravimetric analysis (DTG) of PGU, PGU-1\% APTMS-ZnO, PGU-2\% APTMS-ZnO ${ }^{33}$ 
was dried at 50 ÚC for 1 hour. Finally, the powder was ground and dried at 100 ÚC for 2 hours. In the same vein, Siyanbola et $\mathrm{al}^{8,33}$ also modified $\mathrm{ZnO}$ using 3-aminopropyl-trimethoxysilane.

\section{Characterizations}

The plant seed oils, its polyols, urethanes and composites are usually structurally characterized by the following physico-chemical, spectroscopic and morphological examinations thus acid value, hydroxyl value, iodine value, saponification value, refractive index, specific gravity, viscosity, gel permeation chromatography (GPC), Fourier Transform Infrared (FTIR), ${ }^{1} \mathrm{H}-\mathrm{NMR},{ }^{13} \mathrm{C}-\mathrm{NMR}$, scanning electron microscope (SEM), Transmission electron microscope (TEM), atomic-force microscope (AFM), $X$-ray diffraction analysis (XRD), thermogravimetric analysis (TGA), differential scanning calorimetry (DSC), dynamic mechanical thermal analysis (DMTA) etc.
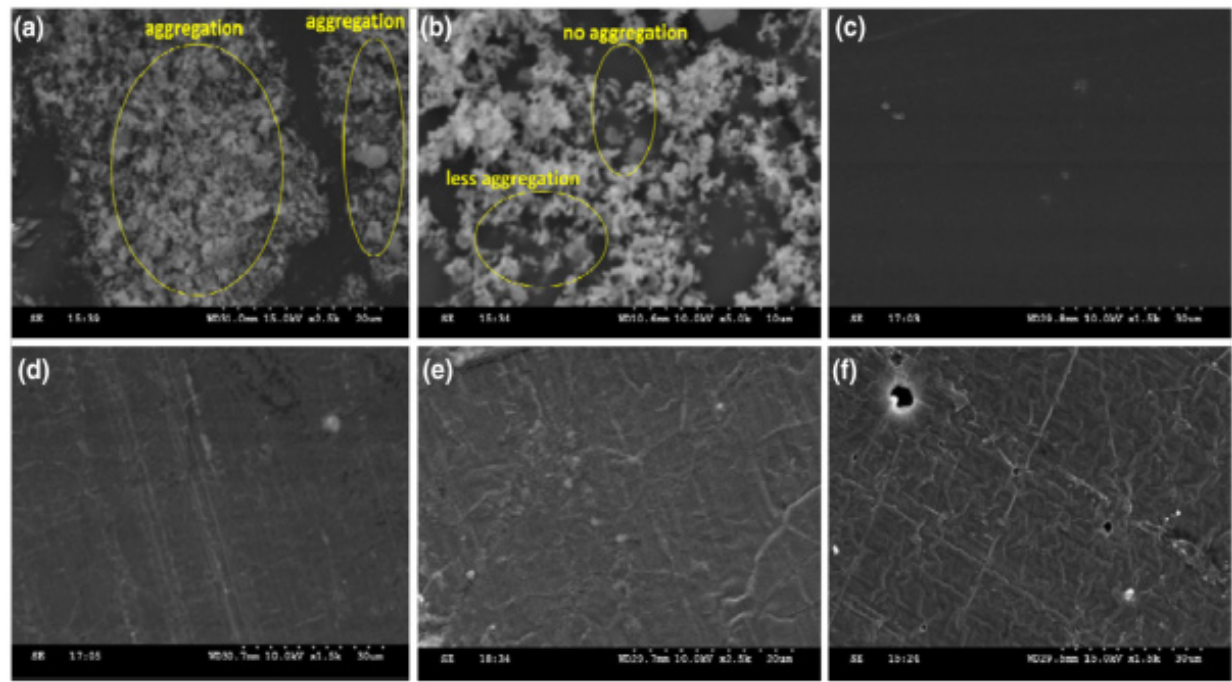

Fig. 3: SEM micrographs of ZnO (a), APTMS-ZnO (b), PGU (c), PGU-1 \% APTMS-ZnO (d), PGU-1.5 \% APTMS-ZnO (e), PG U-2 \% APTMS-ZnO (f) hybrid films ${ }^{33}$

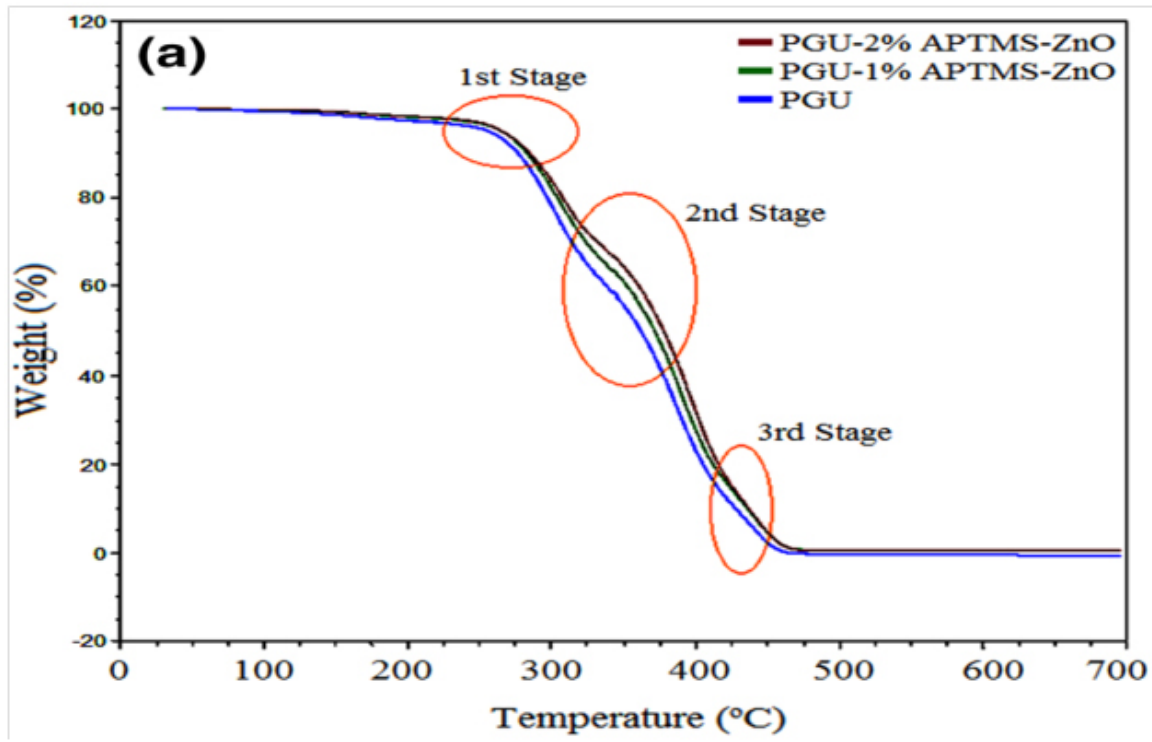

Fig. 4: Thermogravimetric Analysis (TGA) ${ }^{33}$ 


\section{Evaluations \\ Antimicrobial sensitivity}

Over the years, researchers have formulated different types of coatings systems from seed oil base feedstock, which have shown reasonable antimicrobial inhibitive tendency. Siyanbola et $\mathrm{al}^{33}$ compare the antimicrobial sensitivity of pristine polyurethane coating of a partial glyceride polyol and those that have their polymeric matrix doped with $\mathrm{ZnO}$ and modified $\mathrm{ZnO}$ (APTMS-ZnO) in varying percentages. The coating films were tested on gram positive (Staphylococcus aureus and Bacillus subtilis), gram negative (Escherichia coli and Klebsiella pneumonia) bacterial strains and a fungal stain (Aspergillus niger) grown on Czapek-Dox medium. The report shows inhibitive zone beneath and in the surrounding of the coating films. Polyurethane composite of $2 \%$ APTMS$\mathrm{ZnO}$ was found to be highly resistive to growth on Staphylococcus aureus and Escherichia coli. Bacillus subtilis growth was not impaired by the placing of the coating in the medium (as shown on Table 1). The inhibitive activities of the hybrid coatings were perceived to be chiefly as a result of $\mathrm{ZnO}$ nanoparticle present in the composite films Chao et $\mathrm{al}^{34}$. Similarly, Siyanbola et $\mathrm{al}^{8}$ carried out antibacterial activity on the same base seed oil plant (Thevetia peruviana) but on its fatty amide polyol [N,N'-bis (2-hydroxyethyl) Thevetia peruviana fatty amide] urethanes pristine and composites. Though, the synthesized composites in this case contain higher percentages of the hybrid materials, which also reflect on the degree of zone of inhibition. Furthermore, The antibacterial test carried out by $\mathrm{Li}$ et $\mathrm{al}^{31}$ on polyurethane resin composites vividly show the effect of $\mathrm{ZnO}$ nanoparticles percentage increase in the synthesized composites. As the percentage weight of $\mathrm{ZnO}$ increases in the coating system the zone of inhibition increases especially in E. coli.

\section{Thermal stability}

The differential thermogravimetric analysis (DTG) reveals that synthesized coating composites with $\mathrm{ZnO}$ and its modified forms usually have a two stage degradation steps ${ }^{8,35}$. The contrary, were recorded with systems developed by Siyanbola et $\mathrm{al}^{33}$ with a three stage degardation steps (shown in Figure 2). This observation may be due to surface morphology achieved during the coating formulation (Figure 3), which may also be in regard to the material percentage composition within the polymer matrix. The thermal stability of $\mathrm{ZnO}$ and its hybrid coating composites generally increases as the percent composition of materials increases (Figure 4) ${ }^{33,35}$. Siyanbola et al ${ }^{33}$ reported $278.85^{\circ} \mathrm{C}$ onset degradation step for PGU-2\% APTMS-ZnO while PGU-1 \% APTMS-ZnO shows $22.70{ }^{\circ} \mathrm{C}$ less than PGU-2\% APTMS-ZnO. The storage modulus of these coating films also reflects the influence of hybrid composites in the prinstine polyurethane. The modulus profile formation is as a result of strong netmork structures between the urea groups and surface hydroxyl groups on the polyurethane composites through hydrogen bonding. Mishra et $\mathrm{al}^{35}$ also synthesized aquoeus polyurethane hybrid dispersion using nano $\mathrm{ZnO}$ as filler. The research report corroborates the findings about higher thermal stability for hybrid films than that of mother (prinstine) polymer.

\section{CONCLUSION}

The peripheral hydroxyl functional group surrounding $\mathrm{ZnO}$ confers on this oxide robust modification pathways. These product pathways developments have led to the formulation of different coating composites (when the hybrid material is dispersed within the pristine polymeric coatings). These composites are capable of impeding antimicrobial growth and stabilizing thermal interferences.

\section{ACKNOWLEDGEMENTS}

The author Dr. Tolutope O. Siyanbola appreciates Covenant University, Ota, Ogun State, Nigeria for creating true research platform for her faculties.

\section{REFERENCES}

1. World Health Statistics 2009, World Health Organization, 2009.

2. Gabriel, G. J.; Som, A.; Madkour, A. E., Eren,
T.; Tew, G. N.; Mater. Sci. Eng. R: Rep. R2007, $57 ., 28-64$.

3. Alex, K.; Shane S.; Bret J. C.; Prog. Org. Coat., 
2011, 72, 222-253.

4. Donlan, R. M.; Biofilms and Device-Associated Infections. Emerging Infectious Diseases. 2001, 7(2), 277-281.

5. Fristad, W. E; "Epoxy Coatings for Automotive Corrosion Protection”. 2000, doi:10.4271/200001-0617

6. Lu, Y.; Larock, R. C.; ChemSusChem., 2009, 2, 136-147.

7. Siyanbola, T. O.; Ajanaku, K. O.; James, O. O.; Olugbuyiro, J. A. O.; Adekoya, J. A.; Glob J. Pure Appl. Sci. Tech., 2011, 1, 49-54.

8. Siyanbola, T. O.; Sasidhar, K.; Anjaneyulu, B.; Kumar, K. P.; Rao, B. V. S. K.; Narayan, R.; Olaofe, O.; Akintayo, E. T.; Raju, K. V. S. N.; J. Mater. Sci., 2013, 48, 8215-8227.

9. Özgür, Seydibeyoðlu M.; Misra, M; Mohanty, A; Blaker, J. J; Bismarck, A.; Kazemizadeh, M. J.; Mater. Sci., 2013, 48, doi 10.1007/s10853012-6992-z

10. Meier, M. A. R.; Metzgerb J.O. and Schubert U.S., Plant oil renewable resources as green alternatives in polymer science. Chem. Soc. Rev., 2007, 36, 1788-1802.

11. Sharmin, E.; Ashraf, S.M.; Ahmad, S.; Eur. J. Lipid Sci. Technol., 2007, 109, 134-146.

12. Uyama, H.; Kuwabara, M.; Tsujimoto, T.; Nakano, M.; Usuki, A.; Kobayashi, S.; Macromol. Biosci., 2004, 4, 354-360.

13. Changqing, Fu; Zhe, Yang; Zitong, Zheng; Liang, Shen; Prog. Org. Coat., 2014, 77, 1241-1248.

14. Jayakumar, R.; Rajkumar, M.; Nagendran, R.; Nanjundan, S.; J. Appl. Polym. Sci., 2002, 85, 1194.

15. Fangli, Y.; Peng, H.; Chunlei, S. Y.; Shulan, S. H; Jinlin, L.; J. Mater. Chem., 2003, 13, 634637.

16. Nasuaad, A.; Otsego, Y.; J. Colloid Interface Sci., 2006, 296(2), 558-564.

17. Dhoke, S. K.; Khanna, A. S.; Mangal, Sinha T. Jai; Prog. Org. Coat., 2009, 64, 371-382.

18. Li-Piin, Sung; Stephanie, Scierka; Mana, Baghai-Anaraki; Derek, L. H.; Characterization of Metal-Oxide Nanoparticles: Synthesis and Dispersion in Polymeric Coatings Mat. Res. Soc. Symp. Proc. 2013. 740, 15.4.0-15.4.6
19. Hernandezbattez, A; Gonzalez, R; Viesca, J; Fernandez, J; Diazfernandez, J; MacHado, A; Chou, R; Riba, J.; Wear, 2008, 265(3-4), 422. doi:10.1016/j.wear.2007.11.013

20. Greenwood Norman N.; Earnshaw, Alan Chemistry of the Elements (2nd ed.). Butterworth-Heinemann. 1997, ISBN 0-08037941-9.

21. Zhong, Lin Wang; J. Phys. Condens. Matter., 2004, 16, R829-R858.

22. Ko Kodziejczak-Radzimska; Teofil Jesionowski.; Materials, 2014, 7, 2833-2881; doi:10.3390/ ma7042833.

23. Wang, J.; Cao, J.; Fang, B.; Lu, P.; Deng, S.; Wang, H.; Mater. Lett. 2005, 59, 1405-1408.

24. Sawai, J.; Yoshikawa, T. J.; Appl. Microbiol., 2004, 96, 803

25. Padmavathy N.; Vijayaraghavan, R.; Sci. Technol. Adv. Mater., 2008, 9, 1-7.

26. Jena, K. K,; Narayan, R.; Raju, K. V. S. N; Polym. International, 2012, 61(8), 13091317.

27. Mahato, T. H.; Prasad, G. K.; Acharya, B. S. J.; Srivastava, A. R.; Vijayaraghavan, R.; J. Hazard. Mater., 2009, 165, 928-932.

28. Mohammed H.; Abdul Latif; Chemistry and Materials Research. 2015, 7(5), 18-23.

29. Dhoke, S. K.; Khanna, A. S.; Sinha, M. T.; Prog. Org. Coat., 2009, 64, 371-382.

30. Dhoke, S. K.; Bhandari R.; Khanna, A. S.; Prog. Org. Coat., 2009, 64, 39-46.

31. Li, J. H.; Hong, R. Y.; Li, M. Y.; Li, H. Z.; Zheng, Y.; Ding, J.; Prog. Org. Coat., 2009, 64, 504509.

32. Jena, K. K.; Rout, T. K.; Narayan, R.; Raju, K. V. S. N.; Polym. Int., 2012, 61: 1101-1106.

33. Siyanbola, T. O.; Sasidhar, K.; Rao, B. V. S. K.; Narayan, R.; Olaofe, O.; Akintayo, E. T.; Raju, K. V. S. N.; J. Amer. Oil Chem. Soc., 2015, 92, 267-275.

34. Chao, W.; Lian-Long, L.; Ai-Ting, Z.; Peng, X.; Jian-Jun, L.; Xiao-Ting. Z.; Afri. J. Biotech., 2012, 11, 10248-10254.

35. Mishra, A. K.; Mishra, R. S.; Narayan, R., Raju, K. V. S. N.; Prog. Org. Coat., 2010, 67, 405-413. 